\title{
CREACIÓN, VIGENCIA Y RENOVACIÓN DE CARRERAS EN EL DISCURSO ESTRATEGICO DE UNIVERSIDADES CHILENAS. DISCURSIVIDADES DE LOS TEXTOS OFICIALES ${ }^{1}$
}

\author{
Rodolfo JimÉnez CAVIERES * \\ Rigoberto MuÑoz Lagos** \\ Luis Peña Rojas****
}

Recebido em: 03 de agosto de 2009 Aprovado em: 05 de dezembro 2009

\begin{abstract}
*Arquitecto, CMg. Magíster en Educación. Profesor Asociado de la Escuela de Arquitectura de la Universidad de Santiago de Chile; Coordinador del Proyecto MECESUP USACH-Arquitectura. Ha desempeñado el cargo de Director Escuela de Arquitectura (2000-2004) y de Director de Docencia de la Universidad de Santiago de Chile 2004-2006. E-mail: rodolfo.jimenez@usach.cl

**CLLicenciado en Sociología. Desarrolla la tesis "Caracterización discursiva del Ámbito Ufológico vigente en Chile. Aproximación cualitativa al problema sobre los juicios relativos a OVNIS" en la Universidad Academia de Humanismo Cristiano (2009). Participa como investigador adjunto en investigación sobre temáticas juveniles IDEA USACH. E-mail: heme_rigoberto@yahoo.es

***Sociólogo, (CMg. Magíster en Educación. Trabaja en el Instituto de Estudios Avanzados de la Universidad de Santiago de Chile, co-investigador en proyectos FONDECYT No 1070172 "Alfabetismo científico para el chile del mañana: en busca de una definición conceptual y operacional para evaluar el proceso de formación de los ciudadanos del mañana" (2007-2009); FONDECYT No 1040261 Orientación hacia la ciencia y la innovación, y orientación cívicas, en estudiantes universitarios chilenos. (2004-2006); FONDECYT: N $^{\circ}$ 1060988 Evangélicos en chile democrático (1990-2005) ¿Formación de la nueva ciudadanía? (2006-2009). E-mail: luis.pena@usach.cl
\end{abstract}

Resumen: Este articulo analiza los contenidos manifiestos y subyacentes en las prácticas discursivas desplegadas en las estrategias enunciadas por las universidades chilenas en lo referido a la vigencia, creación, mantención y renovación de la oferta de carreras universitarias en el proyecto estratégico de desarrollo institucional que cada universidad presenta como carta de navegación para su desarrollo en vías de enfrentar el desafío de la innovación pertinente con las transformaciones productivas que impone la economía globalizada y su demanda de una nueva formación de profesional para abordar los requerimientos de nuevos productos y servicios.

Palabras-clave: Educación superior. Carreras universitarias. Curriculum. Plan estratégico. Participación.

CREATION, MAINTENANCE AND RENEWAL OF PROGRAMS IN THE STRATEGIC
DISCOURSE OF CHILEAN UNIVERSITIES - DISCOURSES OF THE OFFICIAL TEXTS

Abstract: This article analyzes the undisguised contents and underlying practices unfolded in the enunciated strategies for the Chilean universities in reference to validity, creation, maintenance and renewal of university degree offers, in the strategic project of institutional development that every university has to present as a navigation chart for its development through the challenge of innovation pertinent to productive transformations imposed by the globalized economy and its demand of a new professional education able to deal with the requirements of new products and services.

Key words: Higher Education. College Degrees. Curriculum. Strategic Plan. Participation.

1 El presente artículo es un producto del Proyecto de Investigación DICYT No 2070693 de la Universidad de Santiago de Chile. Análisis y diagnostico de los procesos de creación y evaluación de la vigencia de carreras universitarias: diseño de una propuesta metodológica. 


\section{INTRODUCCIÓN}

Este artículo es una aproximación cualitativa que busca identificar y reconstruir analíticamente la estructura subyacente y de contenido del "texto objeto", implícito en los planes estratégicos, con el objeto de que éstos nos den luces sobre el estado discursivo y de significado en que se encuentran los mencionados textos con motivo de identificar y caracterizar las pautas que guían las políticas de las universidades en torno a la vigencia, creación, mantención y renovación de la oferta de carreras universitaria.

Hasta inicios de la década de los 80', el sistema universitario chileno se destacaba por el mayor predominio de las universidades financiadas por el Estado. En estos años comienza a insertarse diversos mecanismos para el incentivo de la competencia. Se autorizó la creación de universidades privadas con financiamiento propio y se redefinió las formas de financiamiento de las universidades tradicionales. El Estado comienza a asumir un rol subsidiario, otorgando plena autonomía a las instituciones de educación superior para determinar sus planes académicos, gestión de sus recursos y su financiamiento; reservándose sólo el rol de coordinador del sistema de distribución de fondos a la educación superior (BERNASCONI; ROJAS, 2004, p. 31-38). En la actualidad, tanto las instituciones universitarias públicas como privadas tienen derecho a competir para acceder a financiamiento proveniente del Estado; es así que. por una parte, las universidades tradicionales compiten por el Aporte Fiscal Directo (AFD), que se distribuye según numero de alumnos, curso de pregrado, nivel de formación de los académico, número de proyectos de investigación y número de publicaciones; por otra, universidades publicas y privadas compiten por el Aporte Fiscal Indirecto (AFI).

Las modificaciones que se han venido generando en torno a los lineamientos de la educación superior desde la década de 1980 en adelante, guardan relación con el establecimiento del sistema de mercado para la autorregulación y funcionamiento en la entrega de los servicios educativos en el marco de un proceso de globalización económica que produce transformaciones productivas que, más allá de las ventajas comparativas dadas, asumen la innovación permanente como un requerimiento insoslayable que se ubica a la base de la competencia por alcanzar la calidad y la concreción de nuevos productos y servicios y, en el cual la educación superior (y de la educación en general) se debe enfrentar a rediseños pertinentes con esta nueva realidad, que hace que la planificación estratégica se constituya en la norma y que ésta se visualice en planes de desarrollo institucional, que pretenden contener los elementos constitutivos del 
ámbito de preocupación permanente y las propuestas de acción de mediano y largo plazo que deberían aportar al posicionamiento de la institución en el mercado de la educación superior.

\section{REFERENTES TEORICOS}

El supuesto sobre el que se estructura este trabajo es que en los planes estratégicos vistos como textos, es posible visualizar elementos constitutivos que caracterizan la gestión institucional, ya que esta se genera en función de su desarrollo futuro y con relación a la instauración de ideas relativas al posicionamiento exitoso en un espacio determinado del mercado de ofertas educativas.

La posibilidad de establecer el abordaje a los procesos de comunicación desde la perspectiva de las ciencias sociales y mediante el uso de la teoría de la acción social, vislumbra en todo momento como ejercicio propio de la sociología el descubrir el orden social oculto tras el orden simbólico, al decir de García, (1997, p. 23) que el soberano se comporte como soberano, el sujeto como sujeto, el padre como padre y el hijo como hijo", y aun mas, que cada uno no conciba otra "razón de ser" que la que le ha sido otorgada por la dinámica social.

Teniendo como piso teórico, al proceso por el cual se da origen a la producción del mundo simbólico y al sentido que cada individuo o comunidad otorgue en su singular proceso de arraigo cultural a la "construcción social de la realidad" (BERGER; LUCKMANN, 1968), componente esencial que permite por medio de la internalizacion y externalización de estas conductas el dinamismo y la variación de los contenidos sociales e históricos, es que formulamos la asociación de dicho proceso con la mediación de los modos en que se organiza la expresividad, vale decir el uso del lenguaje, sea este verbal, gestual, musical, artístico, etc.

Conjuntamente con tener en consideración al lenguaje como productor y ordenador de la realidad social es que establece la posibilidad de empleo de la teoría bourdieriana sobre la acción, esta se levanta, además de proporcionar una herramienta metodológica, como un aporte epistemológico sobre el problema del objeto en ciencias sociales; emplazando en este sentido conceptos tales como "ruptura" y "juego de espejos" donde sujeto y objeto pierden sus "fronteras" delimitadas constituyendo así las bases epistemológicas de las concepciones sobre re-flexibilidad y vigilancia (BOURDIEU, 1982), con lo que logra establecer una teoría viable con relación a la interpretación de las acciones y las expresiones del lenguaje en tanto causales de los procesos que 
llevan a cabo las sociedades en función de las pautas por las cuales sus agentes se relacionan, ordenan, estratifican y/o jerarquizan, representando a la sociedad dividida en diversas estructuras, donde se distribuyen de singular manera, diferentes tipos de capital. De esta distribución se conformarán los roles que cada individuo ejecuta, estando además en permanente renovación o consolidación el denominado proceso de dominación simbólica.

Siguiendo a Bourdieu, es dado el expandir dicha forma relacional de distribución de capitales simbólicos a las múltiples esferas de lo social en tanto se distinga en el grupo o institución una estructura de legitimidad dada; a la cual Bourdieu calificara con el nombre de campo y que Sánchez (2007, p. 6), siguiendo a Gutiérrez (1995), explicitara: Bourdieu define el concepto de campo como un conjunto de relaciones de fuerza entre agentes o instituciones, en la lucha por formas específicas de dominio y monopolio de un tipo de capital eficiente en él y, como nos propone a su vez García (1997, p. 63):

si tomamos el espacio social, genéricamente entendido, como un 'conjunto organizado o, mejor todavía, un sistema de posiciones sociales que se definen unas en las otras' podemos comprender el campo social de Bourdieu como un 'espacio social especifico' en el que esas relaciones se definen de acuerdo a un tipo especial de poder o capital especifico, detentado por los agentes que entran en lucha o en competencia en ese espacio social.

Entonces es dable considerar bajo el concepto de campo académico en donde se desenvuelve la gestión institucional de las universidades. Mas aún cuando Sánchez (2007, p. 6-7) entiende el campo académico como

un espacio complejo compuesto por productores (investigadores y académicos), distribuidores (profesores e instancias de difusión), consumidores (estudiantes, investigadores y estudiosos) e instancias legitimadoras y distribuidoras del bien (universidades e institutos de investigación).

A través del concepto de legitimidad se establecen las diferencias entre los distintos tipos de capitales al interior de determinado espacio social y con determinado tipo de habitus. En nuestro caso, los discursos virtuales oficiales universitarios sobre la aplicación de modelos estratégicos con mira al futuro de cada institución. Para Sánchez (2007, p. 6):

este espacio se caracteriza por relaciones de alianza entre los miembros, en una búsqueda por obtener mayor beneficio e imponer 
como legítimo aquello que los define como grupo; así como por la confrontación de grupos y sujetos en la búsqueda por mejorar posiciones o excluir grupos. La posición depende del tipo, el volumen y la legitimidad del capital y del habitus que adquieren los sujetos a lo largo de su trayectoria, y de la manera que varía con el tiempo. De ahí que campo, capital y habitus sean conceptos ligados.

Las universidades chilenas en su totalidad, se establecen como entes promovedores del reclutamiento, adiestramiento y perfeccionamiento de capital humano calificado, con el fin de robustecer el campo científico y humanístico de un territorio determinado. Esto es parte integrante de sus principios de acción, que en algunas instituciones ha de ser llamado Alma Matter (MARTÍN, 2008) y en otras, "visión" y "misión”, lo que se articula como una dimensión y categoría pertinente para el presente estudio; en ellos se podrán presentar ciertas guías interpretativas de aquello que cada institución de educación superior articula como su práctica discursiva simbólica y en último termino ética.

Estos antecedentes, aparecen como parte constitutiva del uso que de ellos se hace dentro del campo decisional y jerárquico de cada plantel universitario que, como es sabido, se caracterizan por un avanzado grado de complejización debido a que se encuentran imbricados con el uso de teorías de la administración contemporáneas, lo que manifiestamente conlleva en la mayoría de los casos la utilización de actos de habla propios del área especializada y en boga del conocimiento en administración para la conformación del discurso de cada plan estratégico de desarrollo institucional, los que efectivamente no se eximen de construcción y producción intencionada y discursivamente expuesta en términos de un poder reconocido (GUTIÉRREZ et al., 1995), de un discurso institucional; sea con la intención de efectuar juicios de valor, re-direccionar la gestión o articular una determinada manera de llevar a cabo la administración institucional, etc. En definitiva hace suyo la universidad como discurso plenamente legitimo y propio, lo que sin duda es parte del dinámico proceso de poseer identificables propiedades discursivas, tanto del que las pronuncia como de la institución que autoriza y participa de su expresividad. En este punto se establece para Bourdieu, según Gutiérrez et al., (1995, p. 450):

la imposibilidad de búsqueda de poder en las palabras solo por las palabras mismas, de ahí, la necesidad de relacionar a los actos de habla las relaciones entre las propiedades específicas de los discursos y sus referentes institucionales, ya que la autoridad les llega desde fuera de la enunciación.

García, (1997, p. 66) citando a Bourdieu y Wacquant señala que: 
un capital o una especie de capital es aquello que es eficaz en un campo determinado, a la vez en tanto que arma y en tanto que lucha, lo que permite a su detentador ejercer un poder, una influencia, o sea, existir en un campo determinado en lugar de ser una simple "cantidad despreciable.

Dadas las diferentes especies de poder o de recursos en la distribución del capital en un campo específico, se advierte la capacidad de transformación a la que están sujetos los tipos de capital. Por ejemplo, la transformación de capital económico a capital cultural mediante los títulos académicos, que son los encargados de suministrar la legitimidad institucional a dicha forma de capital y viceversa respecto a la transformación que dicho proceso con lleva con relación a su rol en la obtención de capital económico. Empero se advierte que reconociendo el particular peso que posee el capital económico dentro de los tipos fundamentales de capital, no es posible reducir las dimensiones de la realidad social a una variable independiente como el capital económico, ya que con esto no se comprometen en el análisis todas las dimensiones de la vida cotidiana.

En tanto que la justificación general del presente trabajo se mueve por amplios sectores, algunos concernientes al ámbito metodológico propiamente tal, que guardan relación con la importancia de la coherencia interna en relación al contexto de justificación de las investigación científico-social de orden cualitativo, donde la orientación que se define en lo referente a la confección del objeto de estudio es siempre y primordialmente de carácter interpretativo, reconstrucional y por ende hermenéutico, evidenciándose así el rol primordial que ejerce el contexto justificativo como expresión de coherencia y de vigilancia epistemológica en este tipo de metodologías. (BOURDIEU, 1987, p. 11-17)

Las prácticas investigativas científico-sociales poseen componentes distintivos al momento de pensarlas como un conglomerado de recursos objetivadores vinculados a la construcción del objeto de estudio. Son entendidas como descripciones detalladas de situaciones, eventos, personas, interacciones y comportamientos que son observables, ya que en definitiva se manifiestan en forma textual, es el texto y su estructura discursiva lo que induce el análisis.

De este modo son parte constitutiva y sustancial del presente enfoque metodológico las expresiones, reflexiones, experiencias tal y cual los agentes e instituciones sociales involucradas las señalan; teniendo en consideración al lenguaje como parte integrante de la realidad social en tanto, realidad cultural.

Las ciencias sociales, articulan sus formas de conocimiento a través de las observaciones, las que pueden ser de dos tipos: observaciones de hechos y observaciones de acciones. Estas ultimas solo permiten su entendimiento (y 
así hasta cierto punto su predicción) por medio de alguna teoría, aunque esta sea de "formato mínimo" (GUTIÉRREZ et al., 1995), vale decir, relacionada exclusivamente con el agente que produce la acción. La tarea de las ciencias sociales se ve facilitada por el carácter expresivo de las acciones humanas, las que proveen la señal más directa y manifiesta de la estructura de la subjetividad y del sentido de las acciones, como indica Gutiérrez et al., (p. 178) "no solo actuamos, sino que en el curso de nuestras acción y en relación indisociable con ellas, expresamos el sentido de esa acción".

\section{ESTRATEGIA DE INVESTIGACIÓN}

Se señaliza lo que hay en un párrafo seleccionado, cuya importancia esta dada por encontrarse allí la "palabra-clave- en - contexto" (GUTIÉRREZ et al., p. 192). Las metodologías cualitativas, asumen en todo momento la inseparable relación entre el observador y la forma en que este construye su objeto de estudio. Esto se pone de manifiesto cuando se parte de la base que lo que está bajo análisis es un proceso comunicativo. Las razones que se tienen para estar especialmente interesado en aquellas expresiones-objetos (contenido sustantivo) es que estas entregan claridad acerca de lo que se pretende averiguar. Para Gutiérrez et al., (p. 356) las expresiones-objeto pueden recopilarse, compararse y clasificarse con vista a establecer su virtualidad como tales expresiones en relación al sistema de expresión al que pertenecen. Esta tarea es la que hace suya el análisis de contenido.

La selección de estas expresiones-objetos constituyen los componentes esenciales de lo que se conoce como muestreo teórico; es decir, una selección deliberada e intencional de material que sintonice con los objetivos teóricos de la investigación. Por tanto, se trabajará con un muestreo teórico, el que se obtiene durante el proceso de recogida de datos que es la base para la generación teorética. Se trata de codificar y analizar los datos, además de decidir, en el proceso, qué nuevos antecedentes deben recogerse y dónde encontrarlos, esto en función de desarrollar una teoría emergente (GLASER; STRAUSS, 1967). La cantidad necesaria de información recopilada, se basara idealmente bajo el criterio de saturación al que en la presente entrega añadiremos el concepto de riqueza discursiva, la que se fundamenta en la calidad y cantidad de la información obtenida.

Enfatizamos que cuando se hace referencia al "contenido" de un texto (de cualquier realidad expresiva) paradójicamente, se alude a una realidad extra textual, no al texto mismo, sino a algo en relación con lo cual el texto funciona 


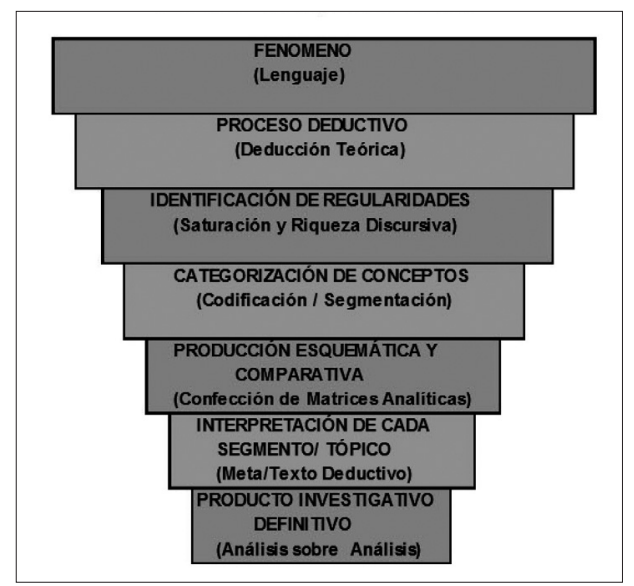

Gráfico 1 - Esquema Análisis

en cierto modo como "instrumento". Entendemos así, que es lícita la promoción pragmática de la metodología cualitativa, que tienda a producir los referentes extra-textuales que complementaran las conclusiones y sentencias de la investigación. Teniendo presente que, como se expresa en Gutiérrez et al. (1995, p. 188 ) "el propósito que debe guiar al analista es pasar del plano del producto (el texto) al plano de la producción textual", las dimensiones analíticas en el presente estudio tienen por finalidad el producir por medio de un conglomerado de características visibles, identificables y pragmáticamente viables la realización del análisis interpretativo de dichas producciones textuales las que poseen la característica principal de ser virtuales y proporcionar acceso al sentido latente que se presenta como propio de los textos-objetos.

También es importante destacar algunas particularidades de los textos a analizar, que constituyen también decisiones teóricas y de coherencia del estudio: Son los planes estratégicos de las siguientes universidades chilenas, a saber, Universidad de Santiago de Chile (USACH), Universidad de Chile (UCH), Universidad de Concepción (UDEC), Universidad de la Serena.(USERENA), Pontificia Universidad Católica de Chile (PUC), Universidad Metropolitana Ciencias de la Educación (UMCE), Universidad Mayor (UMAYOR), Universidad Católica Raúl Silva Henríquez (UCRSH), Universidad Arturo Prat (UPRAT), que tienen una vigencia temporal (propuesta por la misma institución que los genera) que se extiende entre los años 2005/6 al 2010, lo que define con claridad un espacio de temporalidad definida en función de los criterios que se analizan. 


\section{RESULTADOS: CONNOTACIONES DISCURSIVAS RELEVANTES EN LOS DISCURSOS ESTRATÉGICOS UNIVERSITARIOS}

Presentamos la configuración e identificación de lo que denominamos connotaciones discursivas relevantes de los discursos estratégicos universitarios. Estas tienen por propósito una caracterización exegética de los textos analizados y que a la vez constituyen parte del proceso de investigación en términos de la confección de las conclusiones por categoría de análisis que, para las deducciones analíticas ofrecidas en el presente trabajo constituirán la base sobre la que articularemos nuestras descripciones. Para efectos de mayor referencia, desplegaremos cuadros resúmenes de cada connotación discursiva relevante localizada en el corpus textual. Se sugerirán relaciones comparativas entre las diferentes instituciones, las que podrán ser de coincidencia o distinción.

En relación a las argumentaciones y centralmente pensando en las formas conceptuales empleadas en los cuadros de las connotaciones, comentamos que son confrontadas como formas generales de descripción de las practicas retórico/discursivas, que se plantean desde la interpretación de las acciones y expresiones lingüísticas producidas en los textos por cada universidad. Pretendemos que por medio de la implementación de dichos conceptos, la posibilidad de sostener un sobrevuelo interpretativo que de pistas de las diversas formas dadas entre cada casa de estudio en lo relativo a la creación, vigencia y renovación de carreras; el modelo educativo y los modelos de participación de la comunidad en definición del proyecto estratégico de desarrollo institucional.

\subsection{Connotaciones discursivas sobre la percepción institucional relativa a la demanda social por repliegue o expansión de curriculum y carreras}

Esta categorización guarda relación con la identificación de expresiones y formas de habla que para juicio de la presente producción textual, mantienen algún lazo con el proceso decisional institucional en lo relativo a la vigencia o repliegue de ofertas educativas en áreas especificas y la concurrencia de determinado perfil de alumnado. La demanda social refiere a la percepción que hace suya la institución con motivo del cumplimiento de su rol social. De dicha apreciación se desarrollaran las lecturas institucionales sobre el tema. En este sentido, este concepto aparece además como un proceso de retroalimentación entre la institución y su entorno. 


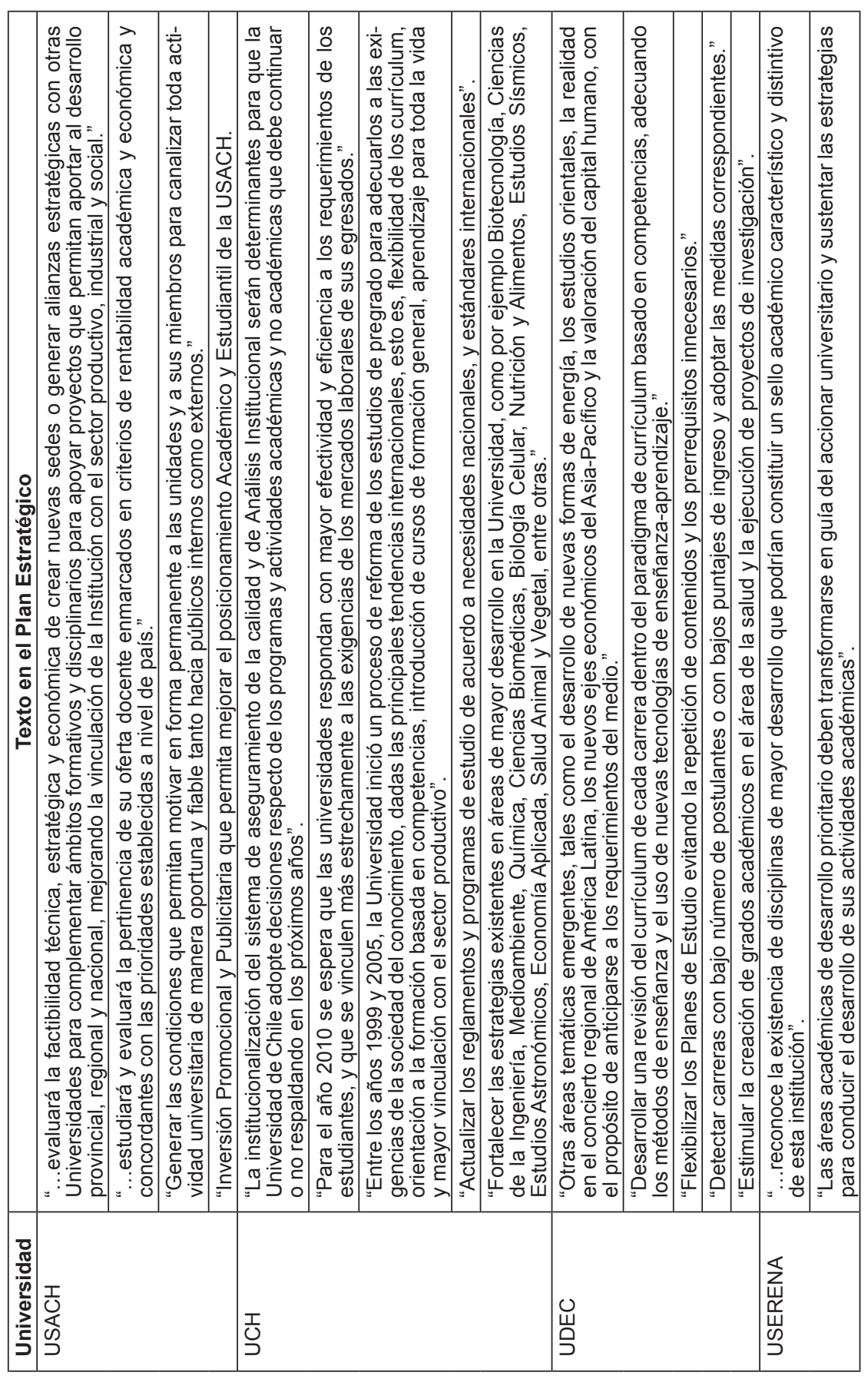




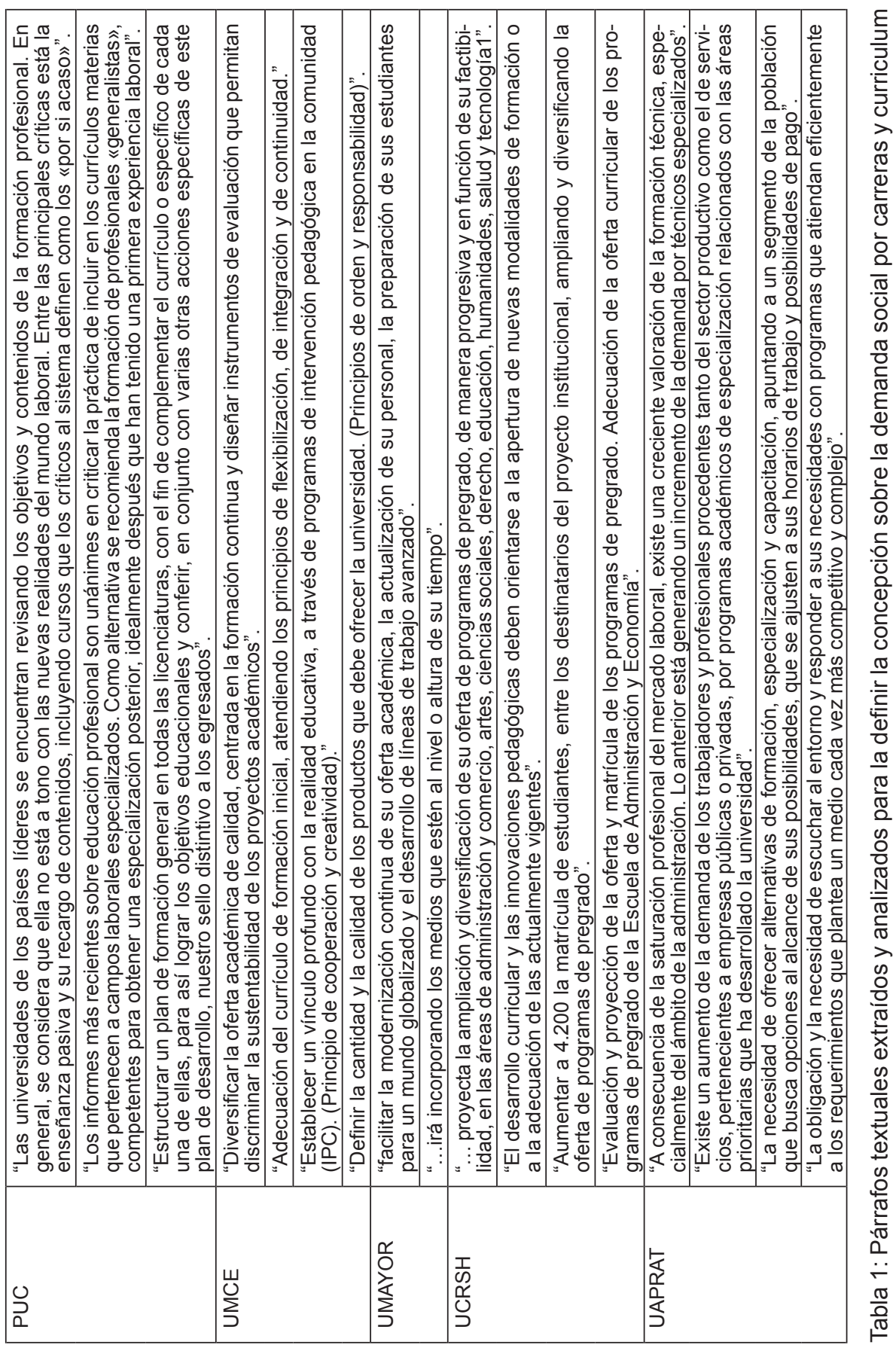


Esta categoría toma por finalidad, la identificación descriptiva de la percepción institucional sobre la demanda por el repliegue o expansión de oferta académica en ámbitos nuevos o consagrados. En este tema se detecta la existencia de una preocupación en la totalidad de las instituciones, las que llevan un monitoreo de las áreas en que se ejerce su desempeño.

Esta preocupación toma diversos rumbos dependiendo del tipo de universidad de la que se tenga como referente. Así, podemos visualizar por ejemplo que en universidades regionales se vislumbra una marcada tendencia a llevar a cabo la lectura de los requerimientos sociales vistos como la necesidad de diversificación de la oferta de carreras técnicas, para lo cual también se han de tomar las respetivas medidas en cuanto a la flexibilización de las formas en que los estudiantes puedan tener acceso a las instancias de perfeccionamiento y estudio. El siguiente es el resumen:

\begin{tabular}{|c|c|c|}
\hline & INSTITUCIÓN & \\
\hline 1 & USACH & $\begin{array}{l}\text { Expansiva, mejora de gestión administrativa y comuni- } \\
\text { caciónal. }\end{array}$ \\
\hline 2 & $\mathrm{UCH}$ & $\begin{array}{l}\text { Gestión: estándares de calidad legitimados internacional- } \\
\text { mente, mayor desarrollo académico. pro dinamismo en el } \\
\text { ámbito curricular, reformativa }\end{array}$ \\
\hline 3 & UDEC & $\begin{array}{l}\text { Gestión de monitoreo del funcionamiento, reestructuración } \\
\text { y flexibilización pedagógica, Preocupación por áreas de- } \\
\text { terminadas (salud ) }\end{array}$ \\
\hline 4 & USERENA & Priorización académica, búsqueda de imagen a proyectar \\
\hline 5 & PUC & $\begin{array}{l}\text { Reflexión y reformulación de los contenidos curriculares, } \\
\text { creación de plan de formación general, variación hacia } \\
\text { pautas socio-educativas, }\end{array}$ \\
\hline 6 & UMCE & $\begin{array}{l}\text { Proyectividad, reestructuración académica, reestructura- } \\
\text { ción curricular. }\end{array}$ \\
\hline 7 & UMAYOR & Modernización de la oferta académica \\
\hline 8 & UCRSH & $\begin{array}{l}\text { Expansiva y evaluativo de la oferta de pre grado, variacio- } \\
\text { nes al currículo, nuevas modalidades de formación }\end{array}$ \\
\hline 9 & UAPRAT & $\begin{array}{l}\text { Percepción por la demanda en educación técnica, diversi- } \\
\text { ficación curricular, responsabilidad institucional }\end{array}$ \\
\hline
\end{tabular}

Tabla 2: Resumen de los tipos de connotaciones relativas a la percepción Institucional sobre la Demanda Social por repliegue o expansión de currículum y Carreras

Fuente: Confección propia en base al análisis realizado a cada corpus segmentado.

Esta categoría toma por finalidad, la identificación descriptiva de la percepción institucional sobre la demanda por el repliegue o expansión de oferta académica en ámbitos nuevos o consagrados. En este tema se detecta la exis- 
tencia de una preocupación en la totalidad de las instituciones, las que llevan un monitoreo de las áreas en que se ejerce su desempeño.

Esta preocupación toma diversos rumbos dependiendo del tipo de universidad de la que se tenga como referente. Así, podemos visualizar por ejemplo que en universidades regionales se vislumbra una marcada tendencia a llevar a cabo la lectura de los requerimientos sociales vistos como la necesidad de diversificación de la oferta de carreras técnicas, para lo cual también se han de tomar las respetivas medidas en cuanto a la flexibilización de las formas en que los estudiantes puedan tener acceso a las instancias de perfeccionamiento y estudio.

Se lleva a cabo la lectura relativa a la falta de tiempo dada las múltiples funciones que los individuos deben realizar en el contexto actual. Procesos sociales a los que la universidad deberá adecuarse. Para esto, se despliegan las estrategias necesarias en pos de ofertar un alto grado de flexibilidad horaria y de formas pedagógicas con las que se instruya a los estudiantes.

Por otra parte, las universidades tradicionales, de mayor tamaño y tradición, vuelcan sus argumentaciones sobre la lectura que realizan de los procesos de reflexión internacional en torno al tema de la creciente profesionalización. Algunas, como la PUC, toman medidas concretas, promoviendo un cambio en el tipo de instrumentación de los modelos pedagógicos, reformulando sus currículum y mallas en función de la creación de una formación horizontal básica, sobre la cual el perfeccionamiento se realice de manera deliberativa por el alumno. Es decir, que el alumno logre un mayor grado de libertad en la elección de los créditos para su formación y especialización.

En otros casos, se puede observar que existe una marcada tendencia a la exploración en determinadas áreas del conocimiento, como forma de incentivar la apertura de carreras que vayan a la par de las necesidades del contexto regional. Así, por ejemplo en el norte, se han de promover las áreas de conocimiento relativas a los recursos naturales de la zona, (pesca, minería, etc.), en las sedes regionales de otras latitudes, como en el sur del país, se fortalecerán los currículum destinados a la formación e investigación en áreas como la forestal o la acuicultura.

Todas las tendencias que nombramos y ejemplificamos guardan relación con la percepción que las instituciones analizadas tienen de la apertura o replique curricular. Pero esta percepción no es directamente traducida en términos de una comprobación de la demanda social por determinado tipo de currículum, sino que da la impresión que se da sólo bajo la lectura de una tendencia. En otras palabras, lo que las instituciones educacionales hacen es proyectar va- 
riaciones internas relativas a la incorporación y reestructuración de nuevas concepciones pedagógicas, curriculares y administrativas con motivo de dar forma a los requerimientos de lo que ya las instituciones atienden. Empero no queda nítidamente establecido cual o cuales son los procedimientos internos que conforman la lectura institucional que lleva a tales énfasis y decisiones.

\subsection{Connotaciones discursivas referidas al modelo educacional}

Esta es la mas amplia, en términos analíticos, de las categorías que hemos empleado, se buscó en primera instancia la reunión de formas y expresiones comunicacionales referentes de comentarios, proyecciones, alusiones y puntos de vista institucionales relacionados con el sistema de educación superior actual en sus múltiples y mas variados ámbitos de acción, tanto interna como externamente a la institución. Se trata de identificar asuntos de diversa índole teniendo solo como punto en común que estos guarden relación con las estrategias que cada institución emplea respeto al modelo educacional vigente. Una especie de sondeo donde podremos encontrar críticas, adecuaciones o simplemente comentarios formalizados sobre la generalidad del campo de las políticas educativas y el modelo que las rige y que direcciona las maneras de accionar de las casas de estudios superiores.

Esta es una categoría que pudiéramos considerar mixta, en el sentido de presentarse como una instancia de clasificación de enunciados producidos formalmente por las instituciones universitarias en lo relativo a las externalidades, al entorno en el cual cada institución actúa, este es necesariamente, el campo de la educación superior en Chile. A la par, pueden situarse en esta categoría, juicios relativos a las percepciones y proyecciones que cada institución genera con respecto a las adecuaciones internas que producidas con motivo de variaciones a sistemas educativos internos. 


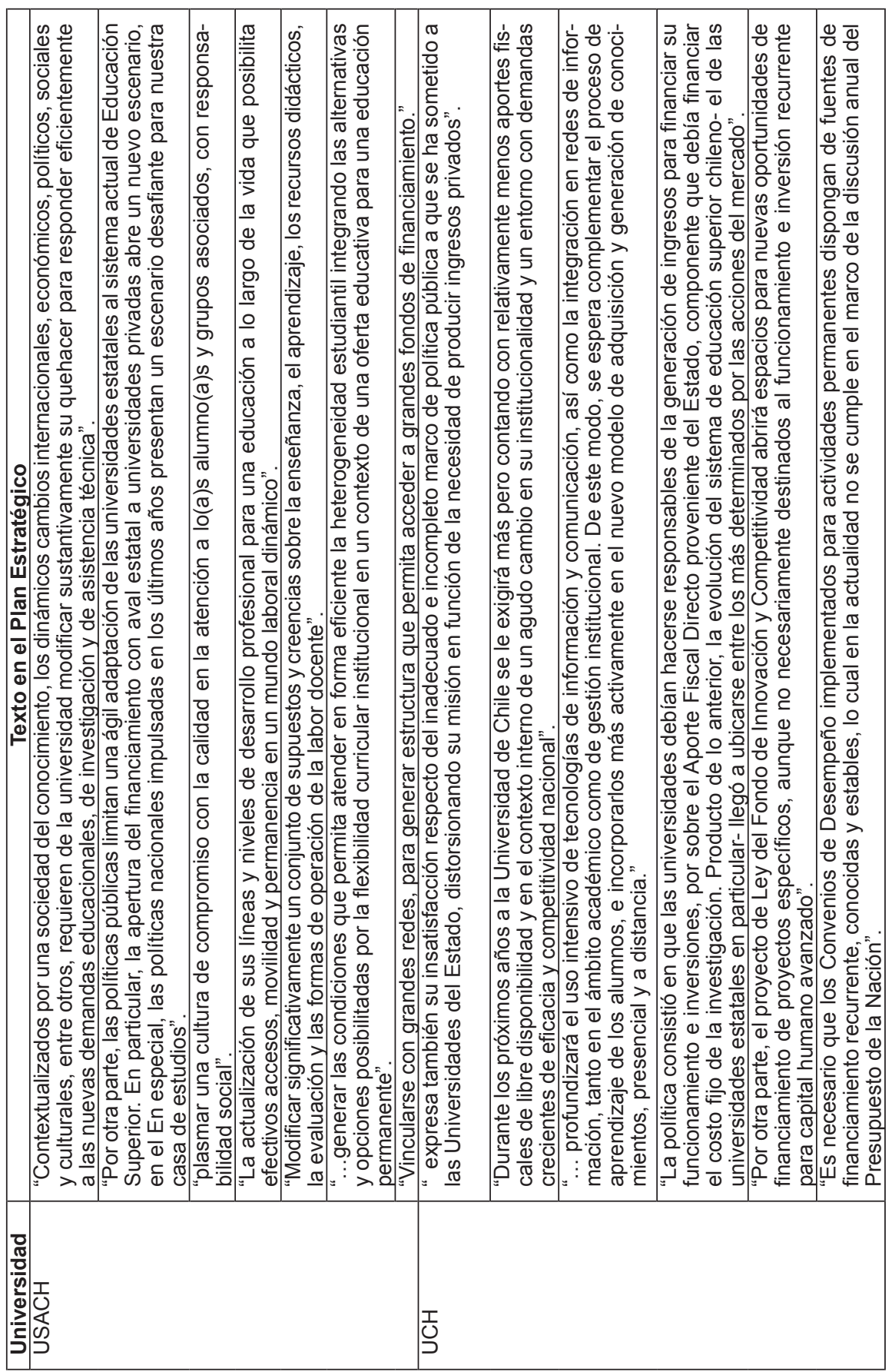




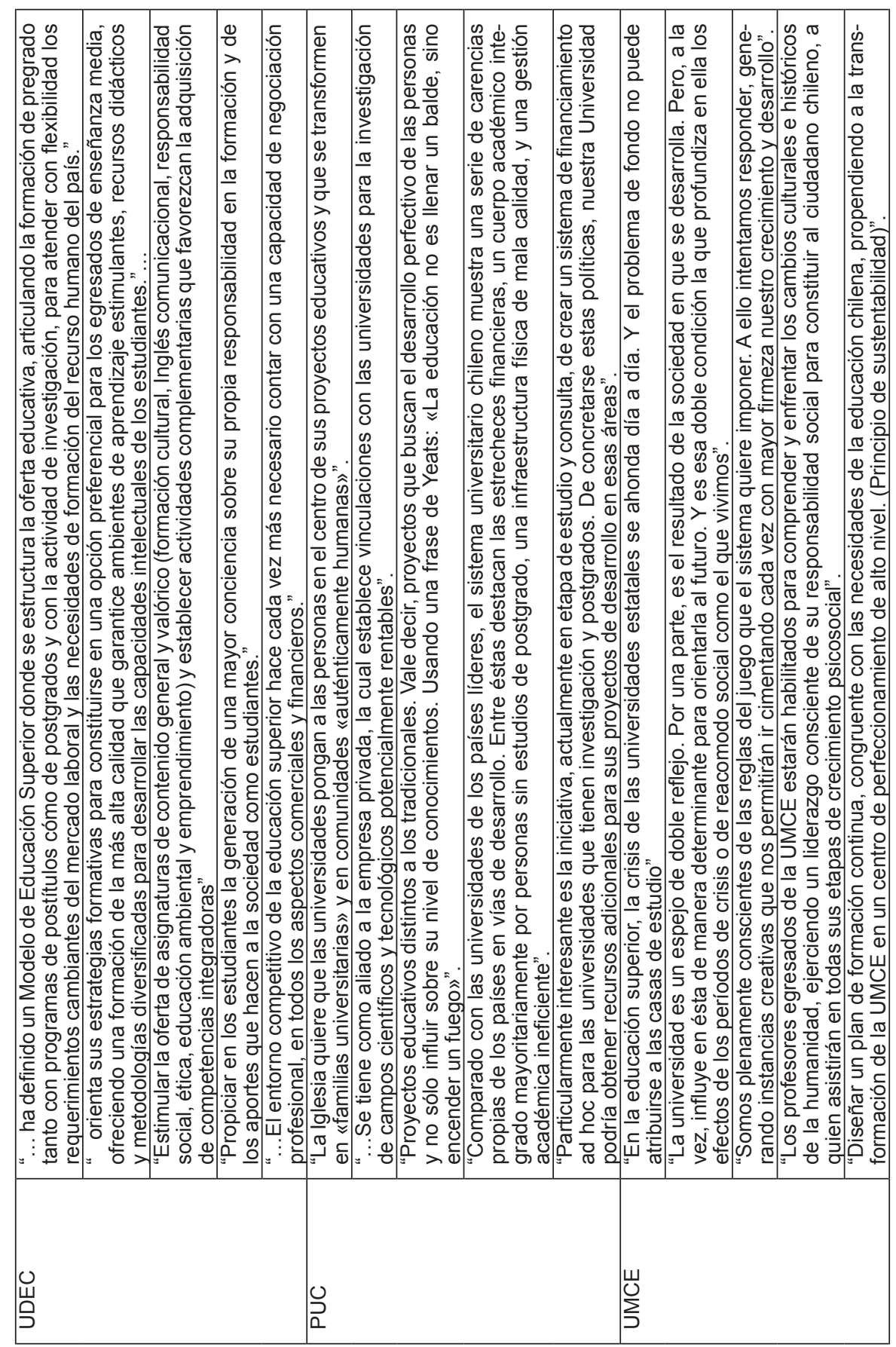




\begin{tabular}{|c|c|c|c|c|c|c|c|c|c|c|}
\hline 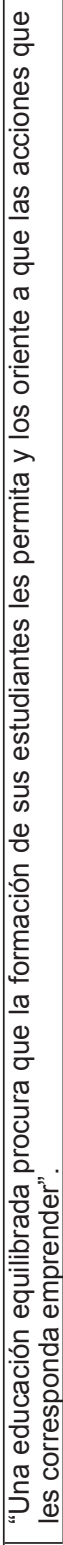 & 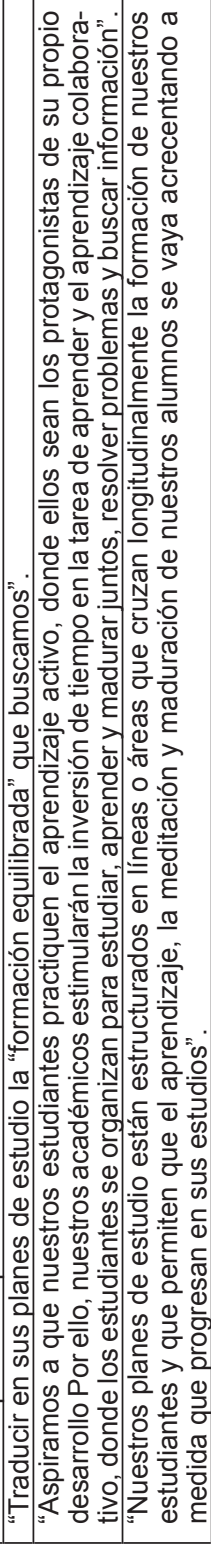 & 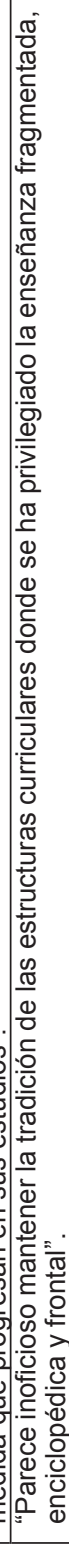 & 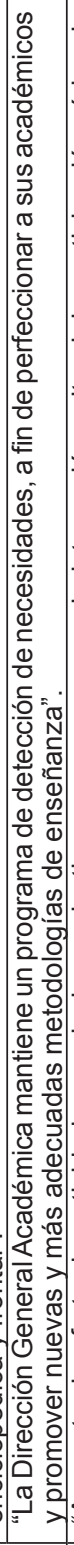 & 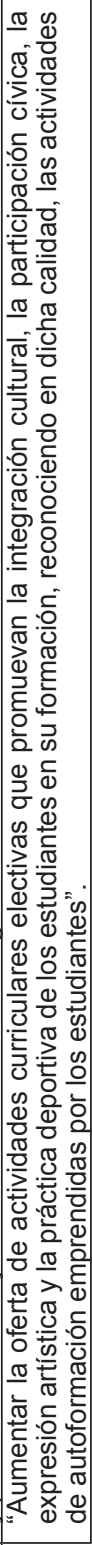 & 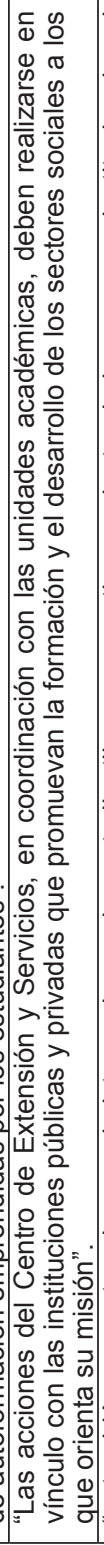 & 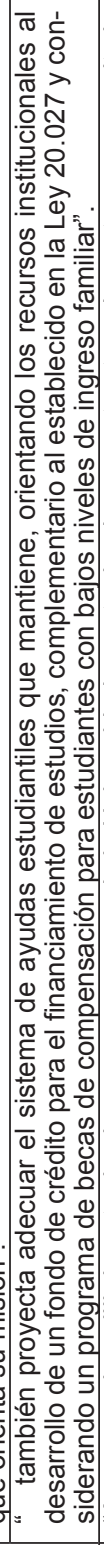 & 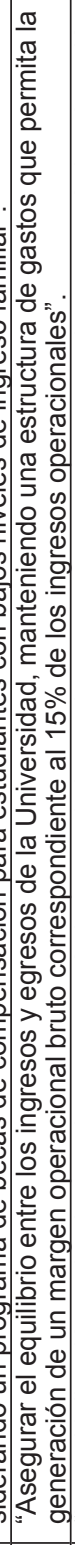 & 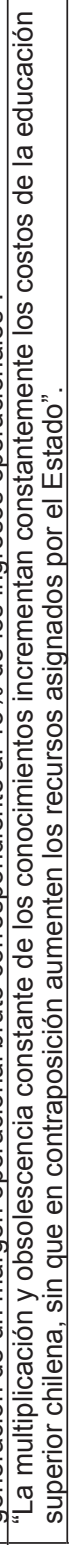 & 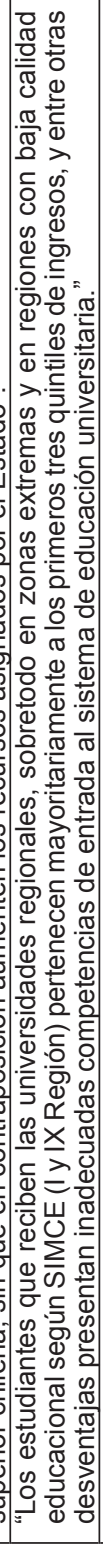 & 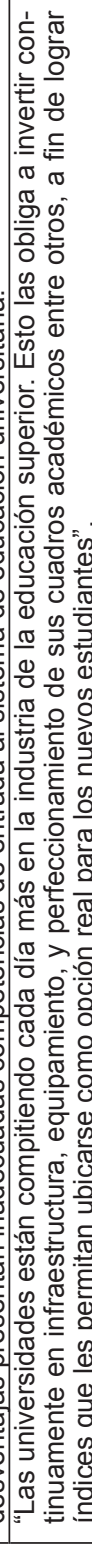 \\
\hline & & & & & & & & & & \\
\hline
\end{tabular}


Las connotaciones aquí presentes cumplen un doble rol, el de caracterizar los procesos de reflexión internos y externos de cada institución, articulando las instancias de textualidad crítica referida a las políticas públicas en educación y al modelo educativo chileno, en otras palabras configurar una pesquisa de cómo reciben las propias universidades las variaciones obtenidas por la aplicación de determinado tipo de políticas públicas de educación superior en Chile en los últimos años. El resumen elaborado se presenta en la tabla siguiente:

\begin{tabular}{|c|c|c|}
\hline & INSTITUCIÓN & \\
\hline 1 & USACH & $\begin{array}{l}\text { Alusiones al entorno social y al rol universitario, comentarios sobre } \\
\text { los nuevos escenarios financieros, evaluación restructurativa de las } \\
\text { prácticas pedagógicas. Preocupación por la heterogeneidad social } \\
\text { en el alumnado }\end{array}$ \\
\hline 2 & $\mathrm{UCH}$ & $\begin{array}{l}\text { Criticas al sistema de educación superior vigente, apoyo a la innova- } \\
\text { ción tecnológica en la gestión académica, }\end{array}$ \\
\hline 3 & UDEC & $\begin{array}{l}\text { caracterización del modelo de gestión académica, competitividad en } \\
\text { las finanzas, desarrollo en el alumnado de competencias sociales }\end{array}$ \\
\hline 4 & USERENA & Nula referencia directa \\
\hline 5 & PUC & $\begin{array}{l}\text { Presentación del "carácter singular" del proceso educativo en la } \\
\text { institución, criticas comparativas en torno al sistema de educación } \\
\text { superior chileno }\end{array}$ \\
\hline 6 & UMCE & $\begin{array}{l}\text { Criticas al sistema de educación superior en chile, inclusión de refor- } \\
\text { mas al sistema de gestión académica interna. }\end{array}$ \\
\hline 7 & UMAYOR & $\begin{array}{l}\text { Fomento al concepto valorativo de educación equilibrada, criticas a } \\
\text { las estructuras pedagógicas tradicionales. }\end{array}$ \\
\hline 8 & UCRSH & Acciones modeladoras del sistema propio de enseñanza \\
\hline 9 & UAPRAT & $\begin{array}{l}\text { Criticas al sistema de educación superior (externalidad) y a su } \\
\text { modelo de financiamiento, alusiones a la actualización del régimen } \\
\text { pedagógico interno. }\end{array}$ \\
\hline
\end{tabular}

Tabla 4: Resumen de los tipos de connotaciones referidas Modelo Educativo Fuente: Confección propia en base al análisis realizado a cada corpus segmentado.

En base al escrutinio de los datos recaudados, podemos sostener que en primer lugar, las instituciones que se permiten criticas generales al modelo educativo y a las políticas publicas, son marcadamente las universidades tradicionales o publicas. Mientras las privadas desplazan sus juicios a asuntos concernientes exclusivamente al ámbito del manejo interno de programas y/o variaciones a los modelos pedagógicos propios. Por otra parte, identificamos nociones tendientes a la reconfiguracion para la puesta al día referida a pro- 
cesos de gestión académica vigente en el contexto de la denominada sociedad del conocimiento. Da la impresión que se explican y establecen a modo de guía, los procedimientos por los cuales cada institución busca su legitimación contextual. Las más grandes lo hacen pensando en la validación en ranking y estándares internacionales desplazando sus preocupaciones en esta materia hacia una visión más bien globalizada de la educación superior.

Las otras, principalmente instituciones con sedes regionales, buscan mejorar su posicionamiento por medio del desarrollo de cierto tipo de área de conocimiento e investigación en particular, buscando que a la larga se incite a un alto grado de especialización en determinadas áreas. En otras palabras, se propone la especialización institucional en pos del reconocimiento distintivo de ser especialistas en dicha área determinada del conocimiento, de esta manera se daría paso a la adquisición de un cierto grado de identidad institucional, la que ligando el desempeño académico, con el reconocimiento social pudieran lograr éxito en el proceso de crecimiento institucional.

Por otra parte y no sin un grado menos de paradoja respecto a las estrategias que se plantean en vista al mejor posicionamiento en el mercado, se encuentran las críticas al sistema de educación superior chileno y las orientaciones otorgadas a las políticas públicas vinculadas con el que hacer de las universidades.

Como punto central de las críticas al sistema educativo, podríamos citar a las formas de financiamiento para las instituciones educacionales universitarias promovidas por el Estado. Detectando que por medio de estas inclinaciones del modelo educativo, se ha producido el fenómeno del vuelco de las universidades a las estrategias de mercado para la subsistencia y la competencia por acaparar mayores grados de financiamiento. Manifestándose una critica pero a la vez un acatamiento y una preparación pensada en base a seguir los requerimientos establecidos. Es decir se critican los procesos normativos, pero a la vez se pretende estar preparado para desenvolverse de la mejor forma posible en los escenarios criticados.

Otro punto que es destacable reseñar, es el que guarda relación con la preocupación por la calidad en el proceso educativo. Pareciese que la forma en que las instituciones universitarias han incorporado dichas conceptualizaciones, obedece a un proceso polifuncional del concepto de calidad. Por medio de la afinación de este, se pretende lograr la aseguración de un cierto nivel tanto académico como investigativo, a la vez que infraestructural y de gestión, lo que en su conjunto permitirá a la institución desplegar sus funciones en mayor y mejor grado, logrando así el ansiado crecimiento y la solvencia financiera. 


\subsection{Connotaciones discursivas acerca de la participación de la comunidad universitaria en la producción del plan estratégico}

Esta categoría aglutinante del discurso reúne aquellas expresiones dirigidas a dar cuenta de las maneras en que las distintas comunidades universitarias participan en las formas que las tomas decisionales desarrollan, específicamente aquella participación que sea dada con motivo de la configuración del plan estratégico institucional. Vale decir, cómo y de qué manera se establecen los canales de participación al interior de las instituciones con motivo del proceso de confección del plan estratégico de desarrollo institucional.

Empleada como categoría, los grados de participación de la comunidad universitaria, nos ha otorgado la posibilidad de realizar un parangón entre las distintas instituciones analizadas en torno a las cualidades expresadas desde el discurso formalizado de las universidades en lo relativo a las implicancias de los estamentos universitarios en el proceso decisional al interior de cada casa de estudios. Por medio de esta categoría buscamos identificar las instancias que cada institución en particular articula en vista a la colaboración y participación de su comunidad en la toma de decisiones además de la intensidad con la que esta se lleve a cabo.

\begin{tabular}{|c|c|}
\hline Universidad & Texto en el Plan Estratégico \\
\hline \multirow[t]{6}{*}{ USACH } & $\begin{array}{l}\text { "Todos estos antecedentes y los análisis respectivos, fueron discutidos y con- } \\
\text { sensuados en un Taller de dos días que se realizó en Millahue y que contó con } \\
\text { la participación de los directivos superiores de la USACH, de los miembros del } \\
\text { Honorable Consejo Académico, de los miembros de la Comisión de Desarrollo } \\
\text { del Plan Estratégico y de algunos profesores invitados" }\end{array}$ \\
\hline & $\begin{array}{l}\text { "Allí se construyo un mapa estratégico en las cuatro perspectivas elegidas: alu- } \\
\text { mnos y alumnas, finanzas, de procesos internos, de aprendizaje y desarrollo". }\end{array}$ \\
\hline & $\begin{array}{l}\text { "Durante el mes de enero de } 2006 \text {, la Comisión visitó los Consejos Académi- } \\
\text { cos de las distintas Facultades para difundir la visión y el mapa estratégico y } \\
\text { recoger también las observaciones que ellos deseaban hacer a esta etapa". }\end{array}$ \\
\hline & $\begin{array}{l}\text { "A fines de enero de } 2006 \text {, la Comisión desarrolló un Taller que contó con la } \\
\text { participación de los directivos de unidades académicas y administrativas". }\end{array}$ \\
\hline & $\begin{array}{l}\text { "La Comisión entregó una primera versión del documento de trabajo del Plan de } \\
\text { Desarrollo Estratégico } 2006-2010 \text { al Honorable Consejo Académico y recibió las } \\
\text { observaciones hechas por los diferentes actores de la comunidad universitaria". }\end{array}$ \\
\hline & $\begin{array}{l}\text { "La Perspectiva Estudiantes se orienta a lograr la satisfacción del estudiantado, } \\
\text { a través de una propuesta de valor que se le ofrece y a aumentar la calidad } \\
\text { de los estudiantes" }\end{array}$ \\
\hline \multirow[t]{2}{*}{$\mathrm{UCH}$} & $\begin{array}{l}\text { "El Plan Estratégico que contiene este documento es el resultado del trabajo } \\
\text { del Consejo y Senado Universitarios. El Senado cumplió con el objetivo de } \\
\text { preparar un Plan de Desarrollo Institucional que sirviera de base para la for- } \\
\text { mulación de un Plan Estratégico. Presentado en gran parte de las Facultades, } \\
\text { y analizado en el Consejo Universitario." }\end{array}$ \\
\hline & $\begin{array}{l}\text { "Asegurar mecanismos de coordinación efectiva y de seguimiento de asun- } \\
\text { tos relacionados que competen tanto al Consejo Universitario como Senado } \\
\text { Universitario; en particular coordinación del Plan Estratégico con el Plan de } \\
\text { Desarrollo Institucional". }\end{array}$ \\
\hline
\end{tabular}




\begin{tabular}{|c|c|}
\hline \multirow[t]{3}{*}{ USERENA } & $\begin{array}{l}\text { "Este documento fue elaborado por la Dirección Superior de la Institución } \\
\text { sobre la base del análisis crítico y evaluación del Plan Estratégico que orientó } \\
\text { el desarrollo en el quinquenio ya concluido, proceso en el que participaron las } \\
\text { autoridades universitarias, los cuerpos colegiados y la comunidad universitaria } \\
\text { en diversas instancias convocadas para tal efecto". }\end{array}$ \\
\hline & $\begin{array}{l}\text { "La participación concierne a todos los miembros de la comunidad universitaria, } \\
\text { por lo que cada uno deberá contribuir a desarrollarla con todas sus potencia- } \\
\text { lidades en los ámbitos de su competencia". }\end{array}$ \\
\hline & $\begin{array}{l}\text { "(...) como resultado de un proceso de consulta, que garantizó la más amplia } \\
\text { participación, se logró la definición de ocho propuestas de Áreas Prioritarias" }\end{array}$ \\
\hline \multirow[t]{3}{*}{ UMCE } & $\begin{array}{l}\text { "El Plan Estratégico, para los fines de su presentación a la comunidad universi- } \\
\text { taria, tendrá en este documento su versión esquemática. El resultado final será } \\
\text { la consecuencia de la debida y oportuna discusión en las bases académicas, } \\
\text { administrativas y estudiantiles de las políticas y acciones específicas." }\end{array}$ \\
\hline & $\begin{array}{l}\text { "Definir nuevos y mejores procedimientos de participación de la comunidad } \\
\text { universitaria en la toma de decisiones." }\end{array}$ \\
\hline & $\begin{array}{l}\text { "Mantener en pleno funcionamiento la estructura regular de la universidad, } \\
\text { mientras no se determinen cambios totales o parciales a su orgánica, a partir de } \\
\text { procesos comunitarios legítimos y consensuados. (Principio de ordenamiento)". }\end{array}$ \\
\hline \multirow[t]{2}{*}{ UMAYOR } & $\begin{array}{l}\text { "Dentro de un diálogo adecuado y con la participación responsable de todos } \\
\text { sus miembros, teniendo como únicas condiciones el respeto a las jerarquías } \\
\text { y la exclusión de toda forma de violencia". }\end{array}$ \\
\hline & $\begin{array}{l}\text { "En consecuencia, espera de todos los integrantes de su comunidad, la voluntad } \\
\text { permanente de autoexigirse ese nivel de excelencia y de cultivar una voluntad } \\
\text { que rechace la mediocridad y que repudie un contentamiento con los mínimos } \\
\text { o con los éxitos meramente superficiales". }\end{array}$ \\
\hline \multirow[t]{2}{*}{ UCRSH } & $\begin{array}{l}\text { "Fortalecer la participación de los estamentos de la Universidad en los procesos } \\
\text { de toma de decisiones institucionales, evaluando periódicamente la estructura } \\
\text { y cultura organizacional." }\end{array}$ \\
\hline & $\begin{array}{l}\text { "La estructura organizacional de la Universidad debe permitir la coordinación e } \\
\text { integración horizontal de las funciones de gestión institucional y de producción } \\
\text { académica en los procesos de toma de decisiones, orientados al cumplimiento } \\
\text { de sus propósitos." }\end{array}$ \\
\hline \multirow[t]{3}{*}{ UAPRAT } & $\begin{array}{l}\text { "Este plan ha sido construido con la participación de la comunidad universi- } \\
\text { taria, lo que ha permitido además fortalecer los compromisos de desarrollo y } \\
\text { la identidad institucional". }\end{array}$ \\
\hline & $\begin{array}{l}\text { "La universidad propicia la participación e integración en los procesos de toma } \\
\text { de decisiones en todos los niveles, de acuerdo a los procedimientos y norma- } \\
\text { tivas vigentes, así como también el fortalecer y facilitar una comunicación y } \\
\text { coordinación interna eficiente, para el éxito de la organización". }\end{array}$ \\
\hline & $\begin{array}{l}\text { "La universidad propicia la generación de espacios de participación e inter- } \\
\text { cambio de ideas y opiniones de la comunidad universitaria, así como también } \\
\text { promueve la reflexión y el debate sobre el conocimiento y las transformaciones } \\
\text { sociales del país y del mundo". }\end{array}$ \\
\hline
\end{tabular}

Tabla 5: Párrafos textuales extraídos y analizados para la definir la concepción de la participación de la comunidad en la producción del plan estratégico

Identificamos así, la existencia de diferencias en cuanto a la definición de los estamentos que participan en procesos deliberativos internos, ya que en algunos casos se detectó una connotación positiva relativa a las formas instauradas 
en la institución para la participación, manifestando lo provechoso de poseer un alto grado de participación Inter/estamental con motivo de la confección del plan de desarrollo institucional. Diferencias que se exponen en siguiente Cuadro Resumen:

\begin{tabular}{|c|c|c|}
\hline & INSTITUCIÓN & \\
\hline 1 & USACH & $\begin{array}{l}\text { Explicitas pautas de participación de la comunidad en el plan estraté- } \\
\text { gico, positivo dialogo interestamental. }\end{array}$ \\
\hline 2 & $\mathrm{UCH}$ & $\begin{array}{l}\text { Manifiesta estructura legitimada para la participación (Senado uni- } \\
\text { versitario) }\end{array}$ \\
\hline 3 & UDEC & Nula referencia directa \\
\hline 4 & USERENA & $\begin{array}{l}\text { Participación por estamentos en el plan estratégico. Positiva evalua- } \\
\text { ción de los procesos internos de participación. }\end{array}$ \\
\hline 5 & PUC & Nula referencia directa \\
\hline 6 & UMCE & $\begin{array}{l}\text { Amplia Participación estamental en la discusión de las bases acadé- } \\
\text { micas y administrativas del plan, la participación como garante del rol } \\
\text { y el funcionamiento institucional. }\end{array}$ \\
\hline 7 & UMAYOR & Participación normada y jerarquizada. \\
\hline 8 & UCRSH & $\begin{array}{l}\text { Propensión a estructura horizontal de gestión y académica para la } \\
\text { participación en la toma decisional. }\end{array}$ \\
\hline 9 & UAPRAT & $\begin{array}{l}\text { Participación transversal con apego a la normativa interna vigente. } \\
\text { Pro positiva en cuanto a la participación interestamental. }\end{array}$ \\
\hline
\end{tabular}

Tabla 6: Resumen de los tipos de connotaciones referidas a la percepción Institucional sobre la Participación de la Comunidad en la producción del El Plan Estratégico

Fuente: Confección propia en base al análisis realizado a cada corpus segmentado.

La manera de situar la participación, en la amplia mayoría de los casos, se lleva a cabo incorporando exclusivamente a los estamentos con cierto capital institucional, estos estamentos son por lo general el académico y el administrativo, dejando de considerarse el alumnado. Es decir, se establecen criterios transversales en cuanto a las disposiciones de la institución para la participación de la comunidad universitaria, pero no se incluye directamente al estudiantado como parte del conjunto de la comunidad institucional.

En otros casos la referencia ha sido nula, vale decir no se han localizado alusiones ni expresiones relativas a la participación del alumnado en la promulgación del plan estratégico de la comunidad universitaria toda. Por otra parte, en varios casos las referencias a la participación se visualizan como un relato de los procedimientos por los cuales el documento fue confeccionado, 
promulgando dentro de aquel relato los procesos de consulta y participación de la comunidad.

Concluimos que en general, se presenta un relato alusivo a la participación como forma descriptiva del proceso de construcción del plan estratégico, buscándose por esta línea una especie de valorización o legitimación de la forma con que se ejecutan las pautas administrativas y las normativas institucionales, expresadas estas en un claro tono democratizante de la actividad universitaria, subrayando que el proceso de confección del mapeo relativo al desarrollo institucional emerge como una instancia de consulta a la comunidad, destacándose en algunos casos la participación de la misma en la toma de decisiones.

\section{CONCLUSIONES}

La lectura institucional sobre la demanda social relacionada a la planificación y desarrollo de nuevas carreras posee una indirecta importancia en la confección del documento oficial de estrategia y gestión universitaria. Ya que se traduce o codifica en función de decisiones internas y no como percepción de necesidades sociales.

La participación de la comunidad universitaria y de los estamentos presentes en la toma de decisiones estratégicas no se manifiesta explícitamente en la confección del documento oficial denominado Plan Estratégico Institucional, sino que se despliega de diferente manera entre las instituciones y que se aboca a la consulta interestamental, donde solo en un caso se contemplan formalmente las propuestas de los estudiantes, y en segunda instancia es vista como propia del proceso de construcción del plan estratégico.

La universidad moderna ha sido definida como un centro de creación y difusión de conocimiento en todas las ramas del saber, donde comparecen investigadores, estudiantes, administrativos y personal subalterno entre otros. Definición levantada por Bunge (1997, p. 35) en momentos en que observa que en nuestra región asistimos a una crisis universitaria de carácter estructural, las instituciones de formación superior han dejado de ser generadoras de nuevos conocimientos que, en su anacronismo, se encuentran ante el riesgo de constituirse en fábrica de diplomas, en caso de continuar en su estrategia de entrega de conocimiento de lo que han sido los descubrimientos y enseñanzas de otros, esto es, su marcado rol divulgativo más que generadoras de conocimientos verdaderamente nuevos.

Son visibles los componentes extratextuales, referentes a la formulación de críticas o comentarios sobre temas que trascienden el sistema interno institu- 
cional, pero que sin embargo se encuentran relacionados a su quehacer, al que consideramos como el Campo científico en nuestro país.

\begin{tabular}{|l|l|l|l|}
\hline $\begin{array}{l}\text { ACTOS } \\
\text { DISCURSIVOS }\end{array}$ & INSTITUCIONES & COMPETENCIAS & $\begin{array}{l}\text { VOCES } \\
\text { SOCIODISCURSIVAS }\end{array}$ \\
\hline De autoridad & $\begin{array}{l}\text { Jurídicas ("poder } \\
\text { reconocido") }\end{array}$ & Autoridad-legitimidad & Portavoz, delegado \\
\hline Compromisos & $\begin{array}{l}\text { Reglas Morales y } \\
\text { Sociodiscursivas }\end{array}$ & $\begin{array}{l}\text { Coherencia, } \\
\text { sinceridad, seriedad, } \\
\text { cortesía... }\end{array}$ & $\begin{array}{l}\text { Persona social } \\
\text { ("remitente } \\
\text { internacionales") }\end{array}$ \\
\hline Formulas & Rituales & $\begin{array}{l}\text { Lealtad social } \\
\text { ("buena educación”, } \\
\text { etc.) }\end{array}$ & $\begin{array}{l}\text { Papel (compromiso con } \\
\text { posición interactiva) }\end{array}$ \\
\hline Expositivos & $\begin{array}{l}\text { Formaciones, } \\
\text { tipos y géneros del } \\
\text { discurso }\end{array}$ & $\begin{array}{l}\text { Competencias } \\
\text { discursivas } \\
\text { especificas }\end{array}$ & $\begin{array}{l}\text { Posesiones de } \\
\text { enunciación }\end{array}$ \\
\hline
\end{tabular}

*Actos Discursivos Instituciones y Sujetos. Cuadro ( GUTIÉRREZ et al., 1995, p. 16-17)

Las practicas discusivas presentes en los planes estratégicos de las universidades, además de configurarse como sujetos de habla institucional, se presentan como discursos de especial complejidad, debido a que en su confección se emplean conocimientos de teoría y metodología de la administración y de sus diversas variantes hipotéticas, las que en si mismas representan una forma discursiva legitimada con anterioridad (función autovalente del Campo científico). Dicha estructura lingüística, contempla un manejo especializado de cierto tipo de conocimiento científico aplicado a la administración. En consecuencia, los grados crecientes de tecnificación y racionalización abocados al perfeccionamiento de conceptos previamente establecidos es un reflejo directo y particular del tipo de discurso analizado.

En cuanto a los contenidos propiamente establecidos en los textos analizados, se presenta con bastante regularidad la manifestación de las formas organizativas propias de los campos en términos de Bourdieu: se establecen posiciones dentro de una economía y de los cambios ideológicos a nivel de las instituciones garantes del desarrollo científico.

En esta perspectiva es posible traducir que en la perspectiva científica de los regimenes universitarios, la inevitable condición de manejo político para el desarrollo de las condiciones optimas de acumulación de conocimiento, las que sin lugar a dudas en el contexto vigente se entremezclan con la externalidad o campo político propiamente tal, fundamentado por el Estado en torno a los procedimientos establecidos como base para el desarrollo de la Educación Superior. 
Existe una marcada instancia crítica al proceso por el cual se ha llegado a establecer el actual régimen político financiero para las universidades públicas. Se establecen de esta manera, críticas al modelo del Estado para la Educación Superior y su vínculo que, paradojalmente, es cada vez mayormente asumido. La condición de libre competencia en tanto empresas educacionales en competencia entre si y con la clara tendencia a querer adjudicarse grados crecientes de preferencia, tanto en la matricula como en el proceso investigativo, esto ya no con una mirada pensada en la Educación Superior como ámbito garante del desarrollo científico sino más bien relativa a ser viables en la manera en que se han desenvuelto los nuevos roles de las instituciones universitarias en Educación Superior. Lo que nos plantea la pregunta concerniente a la consideración de la Educación Superior como un bien cultural o como una mercancía. La universidad que tradicionalmente fue el espacio del despliegue de los puntos de vista de una institución social con plena autonomía formativa y administrativa, hoy se ve también sujeta a las pautas del mercado.

Se percibe la existencia de diferentes tipos de capitales universitarios, cuyos despliegues toman distintos caminos en cuanto al proceso de administración, así se logran percibir distintas líneas de gestión del conocimiento, las que guían su accionar en base principalmente al posicionamiento y tamaño de la universidad. Cuando hablamos de tamaño, nos referimos a todas las variantes que se juntan para establecer un parámetro que dé cuenta del alcance del manejo del conocimiento que posee la institución, vale decir eventos como, la tradición, el numero de matriculados, la cantidad de investigación, de postítulos, de profesores con mayor o menor experiencia, la proyección internacional, etc., configuran el concepto de tamaño institucional. Donde solo a algunas instituciones les es reconocido el rotulo de tradicionales y grandes (complejas).

En cuanto a la gestión académica y con relación al punto anterior observamos, dentro de las universidades tradicionales analizadas, una tendencia a la formación generalizante, donde los alumnos reciben una serie de cursos básicos y generales afines al área de su desempeño, para luego especializarse en el trascurso de sus estudios, lo que es respaldado por argumentaciones discursivas relativas a una mayor flexibilidad curricular dado el período histórico por el que atravesamos, (la sociedad del conocimiento), donde el crecimiento y la expiación del conocimiento especifico poseen características de amplio dinamismo, por lo que no seria posible una formación especializada desde el pre grado y a lo largo de la formación, ya que los avances tecnológicos y de especialización son bastante vertiginosos. 
En la práctica la muestra discursiva analizada se caracteriza por ser poseedora de la autoridad cognitiva atribuida a los expertos, cuyos parlamentos poseen la singular característica de referirse precisamente a las pautas y modelos organizativos y administrativos a seguir por ellos mismos y sus formas institucionales, es decir llevando a cabo un uso autorreferencial. En el marco de relaciones constituyentes del rol de las universidades como centros de formación y experticia la aplicación de conocimiento experto depende de que se muestre que es relevante para el caso en cuestión, ya como una deducción de sus premisas o como una analogía a casos donde se haya explicado previamente.

Con relación a las formas arguméntales referidas a la toma de decisiones al interior de los planteles, no se han manifestado con la suficiente claridad los procedimientos que se llevan a cabo con tales motivos. Los que se han visto solamente referidos a la participación de la comunidad universitaria en torno a la confección del plan estratégico y a referencias con ínfulas democráticas $\mathrm{y}$ en tono general.

No se establecen referencia a los procedimientos y modelos seguidos por las universidades para la detección de la demanda por carreras nuevas o el repliegue de algunas otras cuya demanda sea baja. Por lo que se hace precisa la sistematización de metodologías tendientes a otorgar un mayor grado de claridad respecto a los procesos relativos a la organización singular de la toma de decisiones al interior de cada universidad con un tono mayormente centrado en las propiedades de cada uno de los campos específicos donde se desenvuelve la acción social propia de cada institución. Vale decir, las formas de estipulación y ordenamiento de los planteamientos relativos a la distribución y lucha por la legitimidad no son los mismos en todos los planteles, esto se hace manifiesto en los modos de organizar los discursos asociados a la proyección institucional en forma de planes estratégicos, por lo que necesariamente para establecer las conexiones con la idea de campo, se debe tener acceso a cada una de ellos por separado de manera de organizar la reconstrucción analítica de dichas esferas en cada ámbito universitario.

\section{REFERENCIAS}

BERGER, P.; LUCKMANN, N. La construcción social de la realidad. Madrid: Amorrortu, 1968. 
BERNASCONI, A.; ROJAS, F. Informe sobre la educación superior en Chile, 1980-2003. Santiago de Chile: Ed. Universitaria; UNESCO, IESAL, 2004.

BOURDIEU, P. Lección sobre la lección. (Edición original: Leçon sur la leçon). Paris: Les Éditions de Minuit, 1982.

BOURDIEU, P. Los tres estados del capital cultural. (Trad. M.

Landesmmann). Sociológica, UAM- Azcapotzalco, México, v. 2, n. 5, p. 11-17, 1987. Disponible en: <http://sociologiac.net/biblio/BourdieuLosTresEstadosdelCapitalCultural.pdf $>$. Accesado en: mayo 2009

BOURDIEU, P. Los usos sociales de la ciencia. Buenos Aires: Nueva Visión, 2000.

BOURDIEU P.; CHAMBOREDON, J. C.; PASSERON, J.C.; AZCURRA, F. El oficio de sociólogo. España: Siglo Veintiuno, 2002.

BRUNNER, J.; ELACQUA, G.; TILLETT, A.; BONNEFOY, J.; GONZÁLEZ, S.; PACHECO, P.; SALAZAR, F. Guiar el Mercado. Informe sobre la Educación Superior en Chile. Santiago de Chile: Universidad Adolfo Ibáñez, 2005.

BUNGE, Mario. Los siete pecados capitales de nuestra universidad y como redimirlos. En: BUNGE, Mario. Vistas y entrevistas. 2. ed. Buenos Aires: Argentina: Editoral Sudamericana, 1997.

CALDERÓN, R. Escuelas de la teoría administrativa. Articulo del curso: planeación y organización, de la licenciatura en Educación. Universidad de Guadalajara, 2001. Disponible en: <http://mail.udgvirtual.udg.mx/biblioteca/ bitstream/20050101/895/2/Lectura_4_escuelas_de_la_teoria_administrativa. swf $>$. Acceso en: mayo 2009.

ESCRIBANO, A. Reflexiones Epistemológicas sobre la Investigación Cualitativa en Ciencias Sociales. Cinta de Moebio, n.8. Santiago: Facultad de Ciencias Sociales Universidad de Chile, 2000.

GARCÍA, A. La violencia de las formas jurídicas. Barcelona: Cedecs, 1997. 
GLASER, B.; STRAUSS, A. The discovery of grounded theory: strategles for qualitative research. New York: Aldine, 1967.

GUTIÉRREZ, J., et al. Métodos y técnicas cualitativas de investigación en ciencias sociales. Madrid: Síntesis, 1995.

MARTÍN, P. El rincón de la norma: Alma Máter, Alma Madre. Per Abbat: Boletín Filológico de Actualización Académica y Didáctica, n. 6, p. 161-164, 2008. Disponible en: <http://www.etclibros.es/n6/n6_26.pdf >. Acceso en: mayo 2009:

OCDE- BID. Revisión de Políticas Nacionales de Educación. La Educación Superior en Chile. Santiago: Ed. OCDE-BID, 2009. (Traducción al español e impresión Ministerio de Educación de Chile,

SÁNCHEZ, R. La teoría de los campos de Bourdieu, como esquema teórico de análisis del proceso de graduación en posgrado. Revista Electrónica de Investigación Educativa (REDIE), Universidad Autónoma de Baja California, v. 9, n. 1, 2007.. Disponible en: <http://redie.uabc.mx/vol9 No $1 /$ contenido/dromundo.html $>$. Acceso en: 05 mayo 2009.

VAN DIJK, T. La ciencia del texto. Barcelona: Paidos, 1983.

ZAMUDIO B.; MATIENZO T.; GIUDICE J. El circuito retórico y su funcionamiento en el aula. LSD Revista de los Alumnos de Maestría en Análisis del Discurso, Buenos Aires, n. 3, 2006. Disponible en: <http:// www.lsdrevista.net/articulos/LSD3/sueltos/LSD3-Zamudio-MatienzoGiudice.pdf $>$. Acceso en: mayo 2009 